\title{
Web Therapy for Internet Addicts: \\ A Case Study of Self-Healing by Social Media Addicts in Indonesia
}

\author{
Nuning Kurniasih ${ }^{1}$ and Julian Amriwijaya \\ Department of Library and Information Science, Faculty of Communication Science, \\ Universitas Padjadjaran
}

\begin{abstract}
This study aims to analyze how the information sources on the internet used as therapy treatment (Web Therapy) by internet addicts, especially social media addicts. The method used is qualitative method based on case study perspective. The method used to collect data incorporates in-depth interview, observation, and literature study. The informants are seven internet addicts who acknowledge themselves as internet addicts, especially social media addicts not by medical diagnostic as one and been using internet sources as a treatment to overcome their mental issue. Triangulation is conducted by interviewing a psychology expert. The study results show that (1) The informants admit that information sources on the internet help them reduce stress while under pressure. (2) The informants admitted the initiative comes within themselves to use information sources on the internet in order to reduce stress. (3) There are some ways for informants to identify their personal problems, that is (a) When they feel like they have no one around to talk with, to share their problems with, they use chatting platform to talk with and positive feedbacks from social media. (b) When they encounter negative psychological condition, they need entertainment from internet sources to be relaxed and refresh. (c) When they need contemplation they will look up for some information sources on the internet which might help them to contemplate. (4) To employ self-healing using Web Therapy, the informants choose (a) Entertaining information sources that can help them laugh and relax (b) Information sources contain references on how to cope with their problems. (c) Information sources that can help them to contemplate when encounter problems. (d) Interactive information sources where they can interact and communicate with friends online. (5) The informants prefer social media such as online games with multiple players, youtube, facebook, online forums longue such as kaskus.com and detik.com, and the form of information including games, movies, music, articles on health, food, humor series, chatting, memes, sarcasms, and satyrs (6) The informants agree that although they feel better after using some information sources on the internet as a treatment for self-healing therapy, but it is only temporary not a permanent one. They are also aware of the significant to face their own problems and cope with it. This study results can be the groundwork for libraries to develop Web Therapy services.
\end{abstract}

Keywords: web therapy, webotherapy, internet therapy, internet addicts, internet addiction, self-healing, self-therapy, social media addicts

\footnotetext{
${ }^{1}$ Korespondensi: Nuning Kurniasih. Department of Library and Information Science, Faculty of Communication Science, Universitas Padjadjaran. Jl. Raya Bandung Sumedang KM21, Jatinangor, Jawa Barat. Email: nuning.kurniasih@ unpad.ac.id
} 
The main goal of library is to provide information needed by users for all necessity including education, research, self-improvement, recreation or entertainment. As for the recreation or entertainment purpose, library provides information sources that can help visitors to relax and release their daily stress. This was the beginning of a new services emergence in the library called Bibliotherapy.

Briefly, Bibliotherapy is defined as using reading materials as therapy media or a guidance providing solution to one's personal mental illness through reading. Written materials regarding Bibliotherapy was printed in 1840 for the first time and acknowledged as part of the librarianship in 1904 (Afolayan, 1992). The advancement of internet provides reading materials as an alternative for library in serving Web Therapy services. However, sometimes users want to deal with their own personal mental illness by treating themselves. For instance, users attempt to look for information sources that can help them reduce their daily stress. This attempt usually based on one's belief that only oneself knows bests one's feeling and how to cope with it. In other words, self-healing is doable because of one's belief system that only oneself can be the best cure for oneself.

Some people who acknowledge themselves as internet addicts have super high rate dependence on the internet. As if they cannot live without internet. This addiction affects on how they cope with problems or personal issues. Internet addicts spend most of their time with the internet, it is more likely for them to "befriended" internet when they have problems. Therefore, this study aims to analyze how internet addicts employ webothrerapy on themselves based upon a case study on self-healing by social media addicts. This study aims to generate contribution to libraries in developing Web Therapy services.

This paper will discuss some of the research questions as follows: 1). What are the opinions of internet addicts towards self-healing using Web Therapy? 2). How do internet addicts find the initiative to do self-healing using Web Therapy? 3). How do internet addicts identify personal issues that can be solved through self-healing using Web Therapy? 4). What kind of information sources used by internet addicts to employ self-healing using Web Therapy? 5). What kind of information media used by internet addicts to employ self-healing using Web Therapy? 6). How are the effects of self-healing using Web Therapy on internet addicts?

\section{Research Method}

This study is a qualitative research based on case study perspective. "The case study method allows investigators to retain the holistic and meaningful characteristics of real-life events," (Yin, 2003). The method used to collect data incorporates in-depth interview, observation, and literature study. The informants are seven persons who acknowledge themselves as internet addicts, specially social media addicts, and has been using internet sources as a treatment to reduce their stress and overcome their mental issue. Triangulation is conducted by interviewing a psychology expert. Data processing and analysis in this research is conducted through the stages as follows: (1) Organize the data (2) Coding of data (3) Analysis of the data (4) Interpretation of data.

\section{Results}

\section{Bibliotherapy and Web Therapy Definitions}

Online Dictionary for Library and Information Science (ODLIS) suggests that "Bibliotherapy is the use of books selected on the basis of content in a planned reading program designed to facilitate the recovery of patients suffering from mental illness or 
emotional disturbance... " (American Library Association (ALA), 2015) . Meanwhile, Web Therapy is "the employment of web resources, e-books and e-journals and the reading of them in the treatment of mental and nervous diseases and disorders. Webotherapy or "internet therapy" is the modern alternative to bibliotherapy self-help treatments" (Noruzi, 2007).

Derived from those definitions above, it can be elaborated that Web Therapy is the complement of Bibliotherapy as the result of reading literatures expansion in the internet era. Bibliotherapy and Web Therapy is used to provide solution for clients' personal issues through reading. The difference between Bibliotherapy and Web Therapy is only on its media, where Bibliotherapy's media is books and Web Therapy's media is website sources. Both Bibliotherapy and Web Therapy need to be planned, programmed, and conducted based on the agreement between clients and therapists.

According to ODLIS, "ideally, the process occurs in three phases: personal identification of the reader with a particular character in the recommended work, resulting in psychological catharsis, which leads to rational insight concerning the relevance of the solution suggested in the text to the reader's own experience. Assistance of a trained psychotherapist is advised" (American Library Association (ALA), 2015).

\section{Therapy Categorization}

Carlbring and Andersson (2006) suggests that internet therapy (interapy) is categorized into four, namely: a). Self-administered therapy or pure self-help; b). Predominantly self-help (i.e. therapist assesses and provides initial rationale, and teaches how to use the self-help tool); c). Minimal contact therapy (i.e. active involvement of a therapist, though to a lesser degree than traditional therapy); d). Predominantly therapist-administered therapy (i.e. regular contact with therapist for a number of sessions, but in conjunction with self-help material; (Scogin, 2003)) in (Noruzi, 2007). Self-healing is the first stage of selfhelp to cure oneself from one's own personal problems. When the self-healing is not working then therapist's help is needed.

\section{Information Sources on the Internet}

The information sources on the internet are including texts, pictures, recordings as well as videos, it is multimedia. In order to obtain credible information sources, internet users need to evaluate the information first. There are some notable components need to be evaluated regarding the credibility of information sources on the internet, including the writer's credibility, knowing the motivations and goals of the sources website, accuracy, reliability, and credibility, as well as novelty (Geogetown University Library, 2009-2016).

\section{Psychotherapeutic Stages}

There are several stages to identify client's problems in the PsychotherapeuticRelationship (J.L.G. de Rivera, 1992), as follows: a). The first and most crucial stage to initiate the therapy is the commitment of time, efforts, and the ability to achieve therapy goals between therapist and the client; b). The therapy process is including three aspects, namely determining the form of therapy, information seeking, and consolidation; c). Transformation stage is the representation of therapy result. There are three points contribute to the permanent result of the therapy, that is: 1). Realizing that problems need to be solved; 2). Strong initiative to change behavior or the problems' cause; 3). Sustainable transformation; d). Termination stage is when the client has proved his capability in functioning his own 
mind, thus the therapist is: a). Handing over client's role to the owner; b). Letting the client takes over his live with his own responsibility; c). Acknowledging client's autonomy.

\section{Self-Healing}

Carl Gustav Jung in Mayer (2011) states that the meaning of self is more comprehensive than ego. A Self is related to the archytype of the collective unconscious. Self-healing is not only psycohoid dimension of the self, but also related to the healing elements in general (Mayer, 2011). Jay Earley (2009) mentioning four qualities of self (The Self) that crucial in psychological healing (Earley, 2009), that is: a). The Self is connected. Within self, we feel close to others and want to connect with others harmoniously and supportively; b). The Self is curious. Within self, we are curious on how people accepting others openly; c). The Self is compassionate. Compassion is a form of virtue and love that arises when one gets hurt; d). The Self is Calm, centered and grounded. This helps people when get in touch with something emotionally strong.

There are some ways for informants to identify which personal problems that can be solved by self-healing using Web Therapy, that is: a). When the problems cannot be discussed with the significant others around them, such as family and friends, then internet is the only solution left; b). Realizing that the only way to overcome the problems is by talking to others, thus by utilizing chatting feature on the internet, including through social media; c). Finding oneself more relax and refresh after playing online games, thus games online is a personal escape when under stress or facing difficult problems; d). When in need of entertainment, then social media such as Facebook is the choice, where they can see and read laughable materials, such as humorous posts, meme, sarcasm as well as satyr posts. In addition, Youtube is another choice where they are able to watch some dramas or funny videos as well as listen to some music then contemplate on it; e). When loneliness attacks, they find social media as the remedy to overcome it. As if there are "friends" out there in social media to whom they can share their happy stories, sad or even anger, and are able to understand them; f). When encounter bad mood, the choices are reading something funny, watching stand up comedy on youtube, or reading some references on how to overcome bad mood on the internet; g). To some informants that emotionally stable and never encounter emotional matters such as bad mood, internet is used as media to improve one's knowledge. They regard the internet as their primary information sources thus without it they are information-less.

The types of information used by internet addicts in conducting self-healing using Web Therapy are: a). Laughable reading materials, such as funny or humorous stories; b). Watching shows that can help them to contemplate; c). Entertaining songs and movies or videos; d). References on how to solve one's problems; e). Memes, sarcasms, and satyrs; f). Online games with multiple players. g). Interaction or communication through chatting features on the internet.

Information media frequently used by informants in employing self-healing using Web Therapy including online games with multiple players, youtube, facebook, google, online forum's lounge such as kaskus.com and detik.com. Meanwhile the form of information including games; movies; music; articles on health, food, and humorous series; chatting; memes; sarcasms; and satyrs.

The informants claim that the therapy using information sources on the internet in employing self-healing is only temporary treatment, not permanent one. They admit that 
everyone needs to face their own problems and cope with it. Internet is a means of temporal distraction awhile, providing refreshment while coping with personal problems.

\section{Internet Addicts' Opinion Regarding Self-Healing Using Web Therapy}

The informants admit that information sources on the internet help them reduce stress while under pressure. Thomee S. (2012) revealed the same findings in his study, which propose although "Stress might come from maintaining a large network of Facebook friends, feeling jealous of their well-documented and well-appointed lives, the demands of replying to text messages, the addictive allure of photos of fantastic crafts on Pinterest, having to keep up with status updates on twitter, and the "fear of missing out" on activities in the lives of friends and family (Hampton, Rainie, Lu, Shin, \& Purcell, 2015), but the findings of PAW Research Centre indicates that "Overall, frequent internet and social media users do not have higher levels of stress (Hampton, Rainie, Lu, Shin, \& Purcell, 2015). Meanwhile, Ericson Consumer Lab's study results indicate "ICT has a positive impact on quality of life as listening to music, spending time on the internet and watching TV are the next most popular means of relieving stress" ( Ericsson Consumerlab , 2012).

Therefore, it can be concluded that Web Therapy can be used as a means to reduce stress and cope with personal problems by the internet users. Some of the personal problems revealed by the informants are: a). Boredom thus needs entertainment; b). Loneliness when there is no one around to talk with thus needs friends online to talk with; c). Bad mood or a mental condition that puts one under pressure thus needs internet, and internet can put one at ease and reduce the stress within.

In conducting a therapy, one needs a therapist. A therapist will seek for the original problems within his client then give solution to cope with it. Therefore, a therapist must have competences, including general competences and special competences; a). General Competences, therapist must have: empathy and sincere intention to help; b). Special Competences, the special competences a therapist must have including: 1). A therapist should have undergone an internship or practice period under the supervision of a well-experienced therapist, thus the results are reliable; 2). Capable to identify client's problems through initiate engage including intake, anamnesis, and diagnostic by seeking for client's complaints. The client needs to know the results of the process. There should be a confirmation whether the diagnostic is true or not. When the client does not agree with the diagnostic then it is the end of the process. On the contrary, when the client agrees with the diagnostic then the therapist should continue to the next stage. Therapist then asks a question regarding client's desire, whether he wants to feel better or not. Then, there should be an agreement between the therapist and client regarding the therapy's goals and target, whether it is a verbal or written agreement. The therapist oblige to elaborate the next stage of the therapy process, what needs to be done, and what are the consequences. There are rights and obligations between both parties. It needs client's strong will and commitment.

However, therapy can be conducted by oneself or known as self-healing. Self-healing can be employed as the initiate stage to overcome personal problems, which can reduce negative feelings into positive one. Positive feeling is a prior condition needed to overcome problems.

\section{The Self-healing Initiative by Internet Addicts}

The study findings indicate the informants frequently use information sources on the internet to reduce their negative feelings such as bad mood, boredom, or loneliness, thus they 
need entertainment and friends to talk with. The informants admitted the initiative comes within themselves to use information sources on the internet in order to reduce stress. It is based on their experiences that spending time on the internet helps them to feel better. In addition, it also comes from friends' recommendation.

Ericsson Analytical Platform's (2011) study results show that people live in the center of big city reduce their stress and tension consecutively as follows: (1) Take a bath; (2) listen to music; (3) spend time on the internet; (4) watch TV; (5) take a walk; (6) spend time with friends; (7) exercise/ play sports; (8) eat something; (9) Read a book; (10) Go shopping; (11) Make love; (12) play games; (13) engage in a hobby; (14) talk on the phone; and (15) get a massage ( Ericsson Consumerlab , 2012). In other words, spending time on the internet is one of the most used means to reduce stress and tension.

\section{How Internet Addicts Identify which Personal Issues can be Solved by Self-healing Using Web Therapy}

Research findings show the informants know best about themselves. They know when they need to use internet to reduce stress and the types of information sources that might help them solve their problems. It is a solid basic in conducting self-healing. When one knows best about his own problems then it is easier to cope with it, on the contrary when one cannot identify his own problems then it will be hard for him to find the solution. Thus, he needs other's help or in this case, a therapist.

The study results indicate there are some ways for informants to identify their personal problems, that is: a). When they feel like they have no one around to talk with, to share their problems with, they use the internet to find friends online to talk with. In this case, they choose chatting platform and positive feedbacks from social media such as facebook or through online forums such as kaskus and detik forum to self-healing; b). When they encounter negative psychological condition, such as bad mood, boredom, or loneliness, they need entertainment to be relaxed and refresh. Some of the information sources on the internet used are online games for multiple players, social media such as Facebook and Youtube to access humorous posts, memes, sarcasm, satyrs, funny videos such as stand up comedies, also various references on how to cope with personal problems, and listen to music; c). When they need contemplation they will look up for some information sources on the internet such as videos or shows and other references, which might help them to contemplate.

One out of seven informants admit that he is emotionally stable and never experience such an emotional problem. Internet is his means to improve skills and knowledge, thus without it he feels information-less.

\section{The Types of Information used by Internet Addicts to Employ Self-healing using Web Therapy}

Research findings indicate to employ self-healing using Web Therapy, the informants choose: a). Entertaining information sources that can help them laugh and relax; b). Information sources contain references on how to cope with their problems; c). Information sources that can help them to contemplate when encounter problems; d). Interactive information sources where they can interact and communicate with friends online.

These types of information sources are chosen based on informants' needs. Each individual articulates the needs of information. The theory of information needs categorizes the need of information into four categories, namely (1) the behavior of user; (2) the nature, 
amount and source of the information being sought; (3) the quality of information; and (4) the timelines of information (Faibisoff \& Ely, 20XX).

This particular result might help librarians when operating Web Therapy services in the library, where librarians are fully aware on types of information sources needed and how to utilize it. However, to be a therapist for Web Therapy services, a librarian needs a special skill set as a therapist, such as a know-how skill in identifying someone's emotional problems. Eventually, a librarian is able to provide solution on a particular emotional problem with a specific information sources therapy on the internet.

\section{Information Media used by Internet Addicts to Employ Self-healing using Web Therapy.}

We are Social released "Digital in 2016", which shows the internet users data in 30 countries, including Indonesia. The data indicates there are 79 million active internet users in Indonesia, and 66 million of it is social media users (Kemp, 2016). It also represents the media chosen by informants. The informants prefer social media such as online games with multiple players, youtube, facebook, online forums longue such as kaskus.com and detik.com, and the form of information including games, movies, music, articles on health, food, humor series, chatting, memes, sarcasms, and satyrs. This phenomenon emphasizes that the platform of information sources chosen related to the platform usage trend in general.

\section{The effects of Self-healing using Web Therapy on Internet Addicts}

Self-healing or self-therapy is not an actual therapy if the problems have not been solved, which is also acknowledged by the informants. The informants agree that although they feel better after using some information sources on the internet as a treatment for selfhealing therapy, but it is only temporary not a permanent one. They are also aware of the significant to face their own problems and cope with it.

Observing the self-healing process on the informants, it is shown how they will feel better when experiencing an emotional release after undergo a strong emotional pressure. The informants confirm to it. The informants regard internet as a means of temporal distraction awhile, providing refreshment while coping with the problems. In psychology, it is called catharsis, when one is only coping with the symptoms not yet solving the problems.

A proper therapy requires well-planned and targeted actions where there is a commitment between the therapist and the client to achieve certain goals. However, the informants have done an excellent self-healing therapy. Self-healing helps them feel better and be more positive. Positive state of minds helps people find best solutions for their problems.

\section{Conclusion}

Derived from the results, it can be concluded that Web Therapy is doable in the attempts to overcome internet addicts' personal problems. However, a proper therapy needs a therapist, where there is a commitment between the therapist and the client on the problems occurring, how to cope with it, what should be done and how the consequences are. It should be well planned and programmed.

Even though self-healing or self-therapy is not an actual therapy, but it is recommended as an initiation stage to reduce negative feelings into positive one. A positive state of mind is a great help for people who need solution for their problems. In other words, the internet usage might give contribution in one's self-development as long as it is well 
designed and and conducted, specially for people who need help but unable to access the help from professional.

Librarians are fully aware on types of information sources needed and how to utilize it. However, to be a therapist for Web Therapy services, a librarian needs a special skill set as a therapist, such as a know-how skill in identifying someone's emotional problems. Eventually, a librarian is able to provide solution on a particular emotional problem with a specific information sources therapy on the internet.

\section{References}

Afolayan, J. A. (1992). Documentary Perspective of Bibliotherapy in Education. Reading Horizons, 33(2), 137-148.

American Library Association (ALA). (2015). Bibliotherapy.

Earley, J. (2009). Self-Therapy: A Step-By-Step Guide to Creating Inner Wholeness Using Ifs, a New, Cutting-Edge Therapy. Minneapolis, USA: Hillcrest Publishing Group.

Faibisoff, S. G., \& Ely, D. P. (20XX). Information and Information Needs. Information Report and Bibliographies, 5(5), 2-16.

Friedman, H. S. (2000). The Self-Healing Personality: Why Some People Achieve Health and Others Succumb to Illness. s.1.: iUniverse.

Geogetown University Library. (2009-2016). Evaluating Internet Resources. from http://www.library.georgetown.edu/tutorials/research-guides/evaluating-internetcontent

Hampton, K. N., Rainie, L., Lu, W., Shin, I., \& Purcell, K. (2015). Social Media and The Cost of Caring. Washington, DC: PAW RESEARCH CENTRE.

Hay, L. L. (2004). You Can Heal Your Life. United Kingdom: Hay House, Inc.

Indarini, N. (2015). Sehat dengan Self Healing: Self Healing, karena Tiap Orang Adalah Penyembuh Terbaik Bagi Diri Sendiri. from http://health.detik.com/read/2015/01/20/123234/2808275/763/self-healing-karenatiap-orang-adalah-penyembuh-terbaik-bagi-diri-sendiri

J.L.G. de Rivera, M. (1992). The Stages of Psychotherapy. Eur. J. Psychiat. 6(1), 51-58.

Kemp, S. (2016). Digital in 2016: We Are Social's Compendium of Global Digital, Social and Mobile Data Trends and Statistics. Singapore: wearesocialsg.

Lin, Y.-H., Chen, R.-r., \& Chang, H.-K. (2012). Analysing information behaviour in structured service encounters: a case of call centre operations. IR Information Research, 17(2), 517.

Mayer, M. (2011). Energy Psychology: Self-Healing Practices for Bodymind Health. Berkeley, California: North Atlantic Books.

Noruzi, A. (2007). Webotherapy: Reading Web Resources for Problem Solving. The Electronic Library, 25(6), 741-756.

Philip Gill, (2001). The Public Library Service: IFLA/UNESCO Guidelines for Development. Munchen: Saur.

Schell, C. (1992). The Value of the Case Study as a Research Strategy. From http://www.finance-mba.com/Case\%20Method.pdf

Scogin, F. (2003). Introduction: the status of self-administered treatments. Journal of Clinical Psychology, 59(3), 247-249.

Yin, R. K. (2003). Case study research: Design and methods (3rd ed.). Thousand Oaks: Sage. 
Zucker, D. M. (2009). Teaching Research Methods in the Humanities and Social Sciences How to do Case Study Research. In S. o. Series, How to Do Case Study Research (p. Chapter 14). Amherst: ScholarWorks@UMass Amherst. 